\title{
Micromachined Membrane Filters for Microwave and Millimeter-Wave Applications (Invited Article)
}

\author{
Gabriel M. Rebeiz, ${ }^{1}$ Linda P. B. Katehi, ${ }^{1}$ Thomas M. Weller, ${ }^{2}$ Chen-Yu Chi, ${ }^{3}$ \\ Stephen V. Robertson ${ }^{1}$ \\ ${ }^{1}$ Radiation Laboratory, EECS Department, The University of Michigan, Ann Arbor, Michigan \\ 48109-2122; e-mail: rebeiz@engin.umich.edu; katehi@eecs.umich.edu \\ ${ }^{2}$ Microwave and Wireless Laboratory, University of South Florida, Tampa, Florida 33620 \\ ${ }^{3}$ Hewlett Packard Co., 1400 Fountaingrove Pkwy., Santa Rosa, California 95403
}

Received 23 July 1996; revised 18 October 1996

\begin{abstract}
Recent developments in micromachining techniques at the University of Michigan have resulted in novel high-performance low-loss filters for microwave and millimeter-wave applications. The idea is based on suspending the filters on thin dielectric membranes to eliminate dielectric loss and dispersion problems, resulting in a pure TEM mode of propagation and conductor-loss-limited performance. The dielectric membrane and the surrounding cavities are built using chemical etching in Silicon and GaAs wafers. The filters are therefore compatible with low-cost IC fabrication techniques and can be combined with planar diodes and transistors to result in active filter networks. Several state-of-the-art filters have been realized including $15-\mathrm{GHz}$ and $20-\mathrm{GHz}$ bandpass interdigital suspended stripline filters, lowpass and bandpass microshield filters at $30 \mathrm{GHz}$ and 90 GHz, microstrip 94-GHz bandpass filters, and a 250-GHz bandpass filter with 1.0-1.5-dB insertion loss. This article reviews the associated fabrication techniques, the different types of transmission lines achieved using this technology, and the measured performance from 15 to $350 \mathrm{GHz}$. The study concludes with a detailed description of the future work in this area. () 1997 John Wiley \& Sons, Inc. Int J Microwave Millimeter-Wave CAE 7: 149-166, 1997.
\end{abstract}

Keywords: filters; resonators; micromachining; microwave and millimeter-wave technology

\section{INTRODUCTION}

Millimeter-wave integrated circuits require lowloss, low-dispersion, planar transmission line structures. Unfortunately, microstrip and coplanar waveguide (CPW) suffer from several problems at microwave and millimeter-wave frequencies. These include dielectric loss, which increases with frequency, as well as dispersion, substrate mode problems, and radiation loss, all of which can be directly associated with the air/dielectric

Correspondence to: G. M. Rebeiz

Contract grant sponsors: NASA Center for Space Terahertz Technology, National Science Foundation, Army Research Office, Pluto Express Program discontinuity inherent to substrate-supported transmission lines.

Typically, substrate-supported structures rely mainly on substrate thinning to improve millimeter-wave performance of planar circuits. An alternate solution to the frequency limitations of planar circuits is to integrate the antennas, components, and/or transmission lines on a thin dielectric membrane using micromachining techniques [1]. This technology was first applied to the millimeter-wave area by Rebeiz et al. for the development of high-efficiency planar antennas, receivers, and power meters [2, 3]. It was then introduced by Katehi et al. to the area of microwave transmission lines in the form of the 
microshield line, which resembles a CPW line in free space $[4,5]$. Radiation loss into surface waves in CPW lines is a function of both $f^{3}$ and $\left(\epsilon_{r}-\right.$ $1)^{2}$, where $f$ is the frequency and $\epsilon_{r}$ is the relative dielectric constant of the substrate [6]. Thus, although radiation loss increases rapidly with frequency, it can be eliminated by using an air dielectric (with $\epsilon_{r}=1$ ). The same trend is observed with parasitic capacitive effects associated with circuit discontinuities. These effects, which occur frequently in filters and power dividers, also decrease substantially with the dielectric constant of the substrate. In addition, removal of the silicon substrate eliminates any loss associated directly with the dielectric and any dispersion related to the dielectric/air interface, and allows a single mode TEM propagation over a very broad bandwidth. In fact, time-domain electro-optic sampling of a CPW line on a membrane has indicated that these lines are capable of propagating signals at frequencies as high as $2000 \mathrm{GHz}$ with low loss and low dispersion [7]. Many different types of transmission lines have also been investigated and will be presented in this article.

Membrane-based circuits are typically large (or long) because the effective dielectric constant is close to 1.0. While this poses no problem above $10 \mathrm{GHz}\left(\lambda_{0} \leq 3 \mathrm{~cm}\right)$, it does preclude the use of distributed circuits on membranes below $5 \mathrm{GHz}$ $\left(\lambda_{0} \geq 6 \mathrm{~cm}\right)$ because it is hard to build large membranes which are mechanically rigid at these frequencies. No rigorous study yet has been done on the mechanical properties of membrane-based

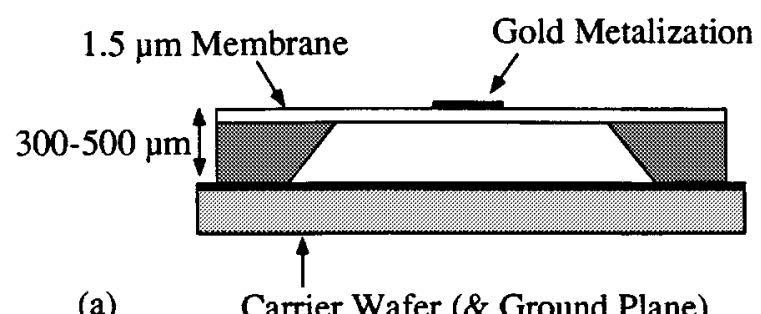

(a)

Carrier Wafer (\& Ground Plane)

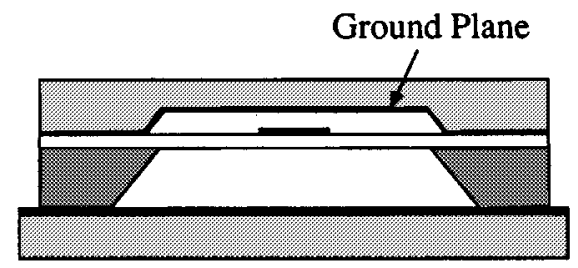

(c) circuits and on the effect of vibration on the electrical performance for different type of filters (narrowband, wideband, etc.). However, it is common knowledge that silicon-nitride membranes are mechanically very strong, can withstand an atmospheric pressure difference without breaking, and survive all laboratory handling procedures. In fact, $30-\mathrm{GHz}$ membrane power dividers and filters with dimensions around $1 \mathrm{~cm}^{2}$, and $0.5-\mathrm{cm}^{2}$ membranes with planar Schottky diodes epoxied on them, have passed NASA's vibration space launch tests $[8,9]$. Finally, it is a common misconception that membrane-based circuits will fail under large temperature variations. These circuits are thermally stable with low residual stress and are routinely dipped in liquid nitrogen $(77 \mathrm{~K})$ or liquid helium $(4 \mathrm{~K})$ with no observed failures. The temperature variation in the performance of a membrane supported component is primarily due to the temperature coefficient of the gold metalization and not to that of the membrane layer.

\section{MEMBRANE-SUPPORTED TRANSMISSION LINES}

The transmission lines developed on membranes are all based on standard substrate supported lines and are presented in Figure 1. The microshield line differs from the standard CPW line by the absence of airbridges between the coplanar ground planes. The reason is that the connec-

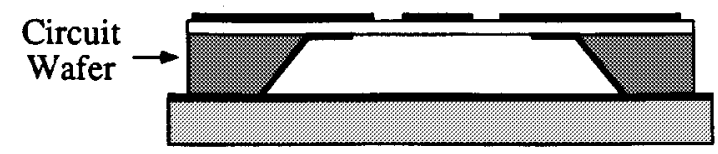

(b)

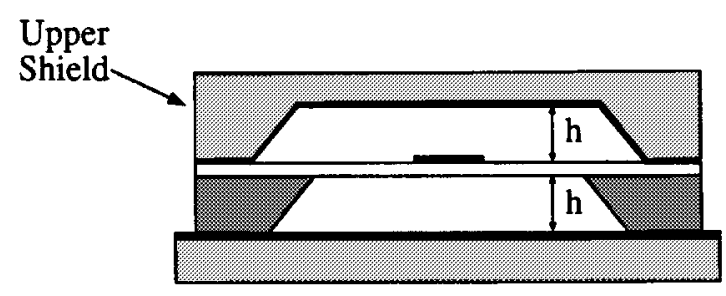

(d)

Figure 1. The different membrane-based transmission lines. The wafers are standard silicon or GaAs wafers and are 300-500 $\mu \mathrm{m}$ thick. 
tion between the ground planes is achieved using the back cavity or "microshield" (and hence the name). The wafers are typically $300-550 \mu \mathrm{m}$ thick and are composed of high-resistivity, silicon (or GaAs) material. The characteristic impedance of these lines is quite high because they are suspended in free space, but the proximity of the ground planes to the transmission lines tends to result in an impedance range of 50-160 $\Omega$ (depending on the geometry). The cutoff frequency of the first order mode in the underlying cavity (transverse dimensions of $0.5-2 \mathrm{~mm}$ ) is around $100 \mathrm{GHz}$ or higher, thereby ensuring a near-TEM operation over a wide frequency range. While the shielded-membrane microstrip (SMM) and stripline structures do not suffer from any radiation loss, attention must be paid to the standard membrane microstrip and for low free-space radiation loss. In the case of the microshield line, the backing metalized cavity confines the fields underneath the line and results in low radiation loss.

The microstrip line, the shielded microstrip line, the stripline, and the microshield line are fabricated using one or two silicon (or GaAs) wafers. The ground plane is not counted as a fabrication step because it does not require any lithographic processing. Silver epoxy is regularly used at the University of Michigan to attach the ground plane to the membrane wafer, thereby resulting in a completely packaged unit.

\section{MEMBRANE FABRICATION AND CAVITY FORMATION}

A three-layer structure of $\mathrm{SiO}_{2} / \mathrm{Si}_{3} \mathrm{~N}_{4} / \mathrm{SiO}_{2}$ is deposited on a high-resistivity silicon substrate using thermal oxidation and high-temperature chemical vapor deposition [10]. The layer must be in tension resulting in flat and rigid membranes. A thermal $\mathrm{SiO}_{2}$ layer with a thickness of $7000 \AA$ is first grown at a temperature of $1100^{\circ} \mathrm{C}$. The wafer is then placed in a LPCVD (low pressure chemical vapor deposition) furnace. A $3000-\AA$ $\mathrm{Si}_{3} \mathrm{~N}_{4}$ layer is deposited at $820^{\circ} \mathrm{C}$. Next, a $4000-\AA$ $\mathrm{SiO}_{2}$ layer is deposited using the LPCVD furnace at $920^{\circ} \mathrm{C}$. The relative dielectric constant of the oxides $\left(\mathrm{SiO}_{2}\right)$ is 3.9-4.0 and that of the nitride $\left(\mathrm{Si}_{3} \mathrm{~N}_{4}\right)$ is $7.0-7.5$ depending on the processing parameters. This results in a dielectric layer which is $1.4 \mu \mathrm{m}$ thick with a relative dielectric constant of 4.70. It is important to note that a membrane layer can also be fabricated using GaAs or InP substrates. In this case, the membrane layer is deposited using plasma-enhanced chemical vapor deposition (PECVD). The deposition parameters of the PECVD layer must be chosen to result in a tensile layer (in contrast to a layer under compressive stress) [11].

After the dielectric layer is deposited on the silicon (or GaAs) substrate, the planar components (filters, couplers, etc.) are defined on the top side of the substrate using standard lithography, gold evaporation, and a $2-3-\mu \mathrm{m}$ gold electroplating process. Next, an opening is defined on the back side of the wafer just underneath the specific components, and the silicon (or GaAs) substrate is etched until the transparent dielectric membrane appears. The etchant used with silicon wafers is $\mathrm{KOH}$ or EDP [12], and both solutions result in a very low undercut rate and smooth sidewalls. The sidewalls form an angle of $54.7^{\circ}$ with the planar top/bottom surfaces when a $\langle 100\rangle$ silicon wafer is used. (The sloping sidewalls are usually assumed to be vertical in the theoretical analysis.) The etchant used with GaAs wafers is an $\mathrm{H}_{2} \mathrm{SO}_{4} / \mathrm{H}_{2} \mathrm{O}_{2} / \mathrm{H}_{2} \mathrm{O}$-based solution or dry etching in an RIE machine [13]. The via holes, if needed, are etched at the same time as membrane formation, and are electroplated with gold.

In the case of suspended stripline or shielded microstrip components (Fig. 1), additional processing is needed to form the top shielding cavity (for stripline) and the RF ground plane (for shielded microstrip). A silicon wafer is etched to the desired depth, electroplated with $2-3 \mu \mathrm{m}$ of gold, and placed on top of the membrane. In the case of microshield lines, shadow evaporation is needed to metalize the sidewalls of the microshield cavity and not the back side of the membrane. This is done using a micromachined mask that is attached to the back of the membrane wafer [14].

\section{STRIPLINE RESONATOR Q-MEASUREMENTS}

Stripline resonators were fabricated on a 350$\mu \mathrm{m}$-thick high-resistivity silicon wafer on a $1.4-\mu \mathrm{m}$ dielectric membrane layer [15]. A top shielding cavity was used at a height of $350 \mu \mathrm{m}$ above the resonator (Fig. 2). The top shielding cavity structure contacts the membrane wafer everywhere except over the $50-\Omega$ grounded CPW feedline (GCPW) where a channel is etched in the top wafer. The channel is $250 \mu \mathrm{m}$ high, $1 \mathrm{~mm}$ wide, 


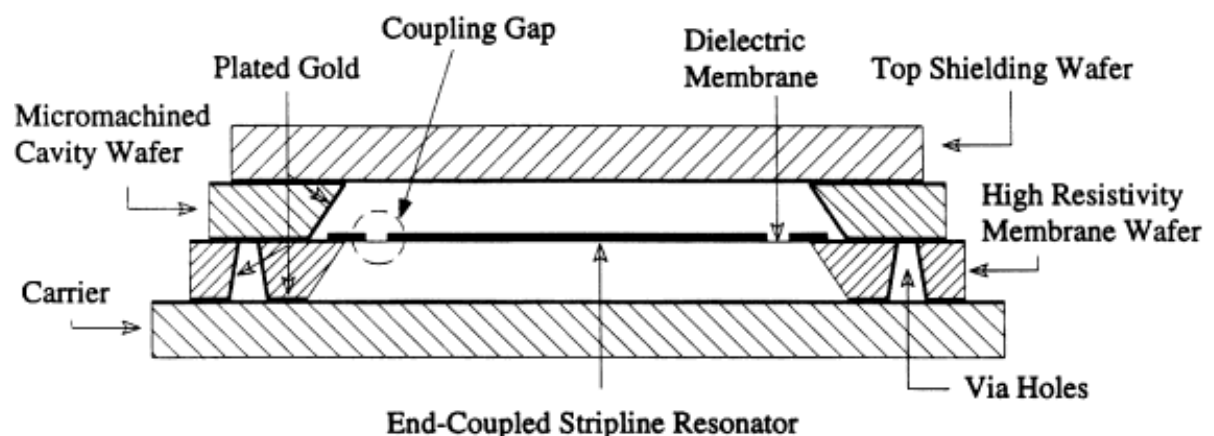

End-Coupled Stripline Resonator

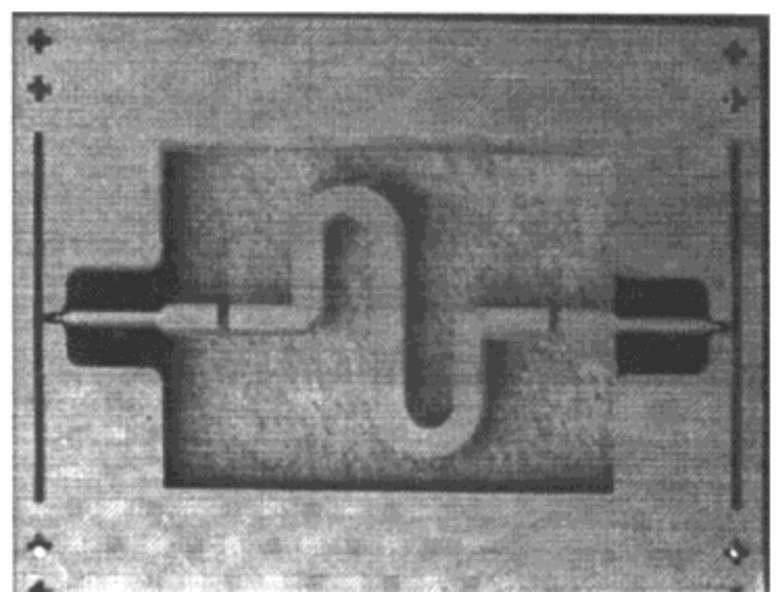

Figure 2. Cross-section view of the micromachined stripline resonator (top) and the fabricated resonator on a thin dielectric membrane (bottom).

$1.5 \mathrm{~mm}$ long, and provides RF microshielding of the feeding GCPW lines [16]. The stripline resonator length is $\lambda_{0} / 2$ at $13.5 \mathrm{GHz}(1.1 \mathrm{~cm})$. The resonator is $500-\mu \mathrm{m}$-wide, $3-\mu \mathrm{m}$-thick electroplated gold. The stripline resonator impedance is calculated to be $80.8 \Omega$ using quasistatic techniques and is fed by $150-\mu \mathrm{m}$ gaps in the feeding transmission line. The membrane dimensions are $7.1 \times 5.3 \mathrm{~mm}^{2}$.

Figure 3 shows the measured $S_{21}$ of the stripline resonators. The resonant frequencies for the stripline resonator are $13.5 \mathrm{GHz}, 27.4 \mathrm{GHz}$, and $39.6 \mathrm{GHz}$ (Fig. 2a). Table I shows the measured loaded $Q\left(Q_{L}\right)$ and the extracted unloaded $Q\left(Q_{u}\right)$, using [17]:

$$
\begin{gathered}
Q_{L}=\frac{f_{0}}{(\Delta f)_{3 \mathrm{~dB}}} \\
S_{21}(\mathrm{~dB})=10 \log _{10} \frac{Q_{e}^{2}}{Q_{L}^{2}}
\end{gathered}
$$

and:

$$
\frac{1}{Q_{L}}=\frac{1}{Q_{u}}+\frac{1}{Q_{e}}
$$

where $Q_{e}$ is the external $Q$ of the resonator. $Q_{e}$ is defined as the $Q$ of the resonator with the series resistance loss set to zero $\left(R_{s}=0\right)$ and, therefore, the resistive loading of the resonator is due only to the loading effect.

As is evident in Table I, the stripline $Q_{u}$ increases as $\sqrt{f}$ with frequency. This is an indication of conductor-loss limited performance and the absence of dielectric and radiation loss mechanisms. The attenuation $\left(\alpha_{T}\right)$ and the total series resistance $\left(R_{s}\right)$ of the micromachined stripline is calculated from the extracted unloaded $Q$, assuming conductor-loss-limited performance, and using:

$$
\alpha_{T}=\frac{\pi}{Q_{u} \lambda}=\frac{R_{s}}{2 Z_{0}}
$$




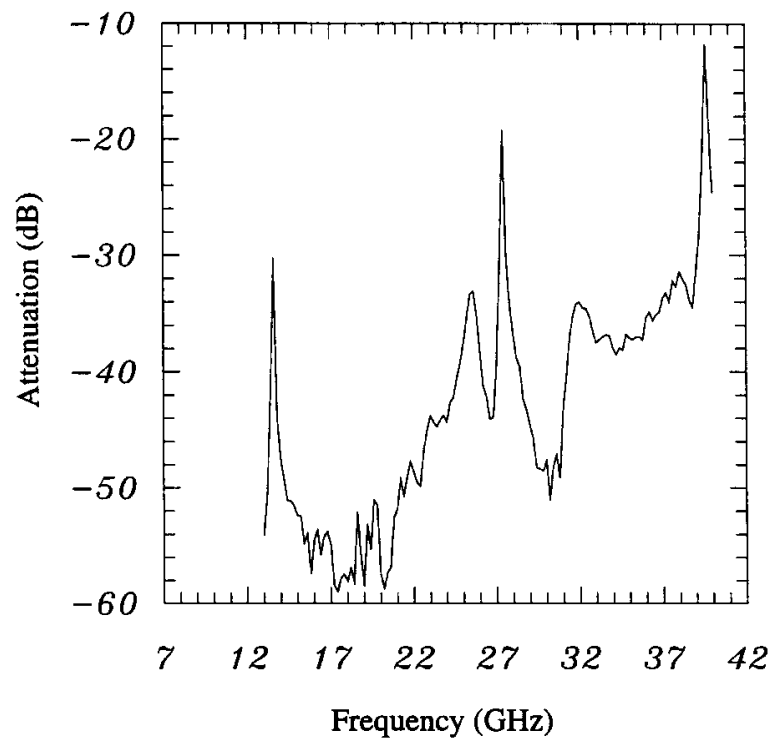

Figure 3. Measured $S_{21}$ of the micromachined resonator.

where $Z_{0}$ is the characteristic impedance of the resonator. The same stripline geometry is analyzed using a new conformal mapping technique developed by Tuncer et al. [18]. The conformal mapping technique uses an isolated-conductor surface impedance in conjunction with a conformal map for the entire transmission line crosssection to account for both skin depth and current crowding effect. Therefore, the conformal mapping model can predict accurately the series impedance of a transmission line for a conductor with finite conductivity and excellent agreement is achieved between the measured results and the conformal mapping technique.

\section{K-BAND-SUSPENDED STRIPLINE INTERDIGITAL BANDPASS FILTERS}

The design procedure of an interdigital stripline filter has been developed by Matthaei et al. [17, 19]. In this work, only the coupling between adjacent resonators has been considered in the admittance/impedance matrices, and a bandwidth correction factor is needed to compensate for neglecting the mutual coupling between the nonadjacent resonators. The membrane stripline interdigital filter results in a pure TEM propagation mode with no dispersion effects. Because of the pure TEM mode, a scale model at $850 \mathrm{MHz}$ can yield accurate simulation of the performance of the $20 \mathrm{GHz}$ filter. Matthaei's equations [17, 19] were first used as a starting point in the scale model and then the lengths, widths, and gaps of the eight finger resonators were adjusted experimentally to obtain in the desired response. The scale model shows a center frequency of 856 $\mathrm{MHz}$, a 3-dB bandwidth of $140 \mathrm{MHz}$, and a portto-port insertion loss of $0.7 \mathrm{~dB}$ (including $0.3 \mathrm{~dB}$ from the input/output coaxial cables). This translates into a center frequency of $20.28 \mathrm{GHz}$ with a 3-dB bandwidth of $3.3 \mathrm{GHz}$ for the micromachined filter.

The $20-\mathrm{GHz}$ interdigital filter is fabricated on a $1.4-\mu \mathrm{m}$-thick membrane with dimensions of 7.9 $\times 3.4 \mathrm{~mm}^{2}$ (Fig. 4). The membrane cavity is surrounded by a row of via holes to ensure proper grounding. A micromachined cavity wafer with a mouse-hole channel is stacked on top of the membrane wafer using silver epoxy and this creates the top cavity for the filter. The mouse-hole channel is needed so as not to short (or severely disturb) the input/output feedlines. Another carrier wafer is stacked below the membrane wafer to form the bottom cavity. Both the top cavity and bottom carrier wafer are electroplated with gold to obtain a good RF ground plane.

The input line is a 2.6-mm-long grounded CPW line on the high-resistivity silicon wafer, and directly feeds the first resonator in the interdigital filter. A $20-\mu \mathrm{m}$ diameter gold wire is bonded across the first finger at the membrane-GCPW transition to equalize the two ground planes of the GCPW line. The bonding wire is important because it forces a symmetrical field distribution at the transition and provides a $50-\Omega$ feeding impedance at the GCPW line. The measured results show a $1.7-\mathrm{dB}$ port-to-port insertion loss at $20.3 \mathrm{GHz}$ (including a $0.3-\mathrm{dB}$ loss from each GCPW line) with a $3-\mathrm{dB}$ bandwidth of $3.1 \mathrm{GHz}$ (Fig. 5). The return loss is better than $-15 \mathrm{~dB}$ in

TABLE I. Measured Q and Rs of Stripline Resonators

\begin{tabular}{lccc}
\hline & \multicolumn{3}{c}{ Stripline } \\
\cline { 2 - 4 } & $f_{01}$ & $f_{02}$ & $f_{03}$ \\
& 13.555 & 27.365 & 39.636 \\
\hline$Q_{L}$ & 258 & 331 & 304 \\
$Q_{u}(\Omega / \mathrm{cm})$ & 272 & 386 & 465 \\
$R_{s}(\Omega / 196$ & 1.439 \\
$R_{s}(\Omega / \mathrm{cm})$ conformal & 0.841 & 1.196 & \\
$\quad$ mapping & 0.762 & 1.153 & 1.410 \\
\hline
\end{tabular}




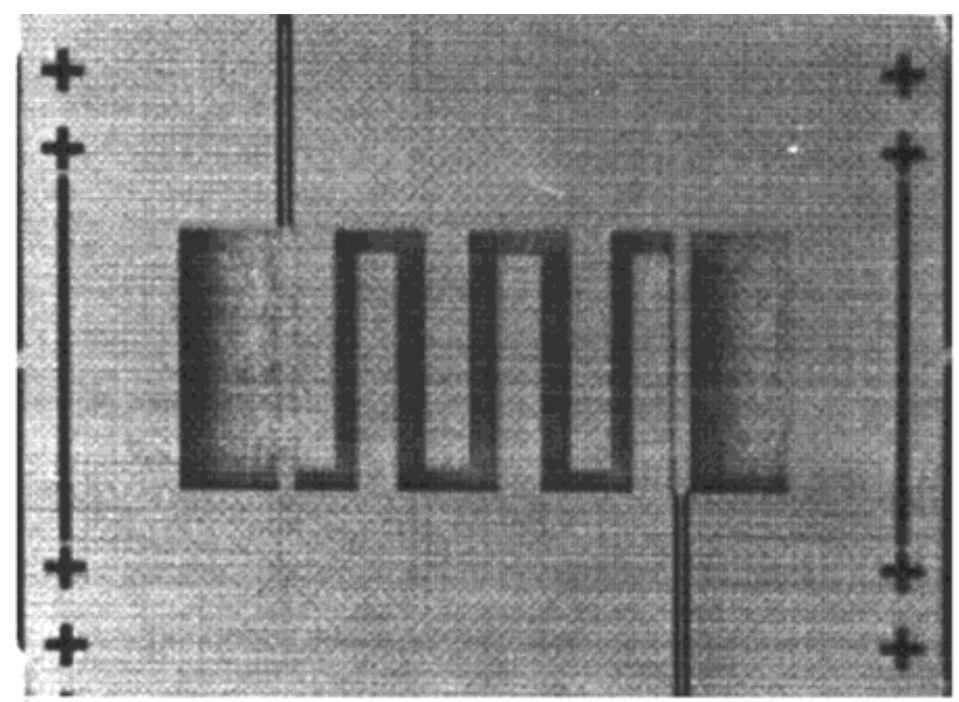

\begin{tabular}{|c|c|c|c|c|}
\hline$K$ & $s_{k, k+1}(\mu m)$ & $K$ & $w_{k}(\mu m)$ & $L_{k}(\mu m)$ \\
\hline 0,6 & 23 & 0,7 & 229 & 3373 \\
\hline 1,5 & 285 & 1,6 & 503 & 3112 \\
\hline 2,4 & 371 & 2,5 & 528 & 3101 \\
\hline 3 & 376 & 3,4 & 577 & 3086 \\
\hline \multicolumn{5}{|c|}{$\begin{array}{ll}K \text { : finger number } & w_{k}: \text { finger width } \\
s_{k, k+1}: \text { gap between fingers } & L_{k}: \text { finger length }\end{array}$} \\
\hline
\end{tabular}

Figure 4. The $20 \mathrm{GHz}$ interdigital membrane filter (top view) and its physical dimensions. The clear area on this picture is the dielectric membrane. The membrane dimensions are $7.9 \times 3.4 \mathrm{~mm}^{2}$.

the passband. As can be seen, excellent agreement is achieved between the $850-\mathrm{MHz}$ design and the 20.3-GHz measurements due to the TEM nature of the micromachined filter (no dispersion effects).

Table II shows a detailed breakdown of the loss mechanism in the suspended filter structure. The resonator loss of the $20-\mathrm{GHz}$ filter is calculated using [17]:

$$
\Delta L_{A}(\mathrm{~dB}) \simeq 8.686 C_{n} \frac{1}{\omega Q_{u}}
$$

It is seen that the measured port-to-port insertion loss of $1.7 \mathrm{~dB}$ is very close to the predicted value of $1.55 \mathrm{~dB}$, indicating, once again, a conductor-loss-limited performance. This also applies to the $850-\mathrm{MHz}$ filter structure.

In addition to the 20.3-GHz filter, wideband 13.5-GHz $(40 \%)$ and narrowband $15-\mathrm{GHz}(5 \%)$ interdigital filters have been fabricated using the same technology [20]. The measured port-to-port insertion losses was $0.7 \mathrm{~dB}$ and $2.0 \mathrm{~dB}$, respec- tively (see Table II). Both of these filters resulted in excellent out-of-band rejection and conductorloss-limited performance in the passband. The suspended stripline interdigital filters can be fabricated using the same technology [20]. The measured port-to-port insertion losses was $0.7 \mathrm{~dB}$ and $2.0 \mathrm{~dB}$, respectively (see Table II). Both of these filters resulted in excellent out-of-band rejection and conductor-loss-limited performance in the passband. The suspended stripline interdigital filters can be fabricated anywhere from 6 to 120 $\mathrm{GHz}$, being limited by the membrane size below 6 $\mathrm{GHz}$ (too large) and by the substrate thickness at $120 \mathrm{GHz}$ (around 80-100 $\mu \mathrm{m}$ ).

\section{MICROSHIELD-LINE RESONATORS AND FILTERS}

Several millimeter-wave filters and components from 30 to $250 \mathrm{GHz}$ have been fabricated using the microshield-line geometry (Fig. 6). The mi- 


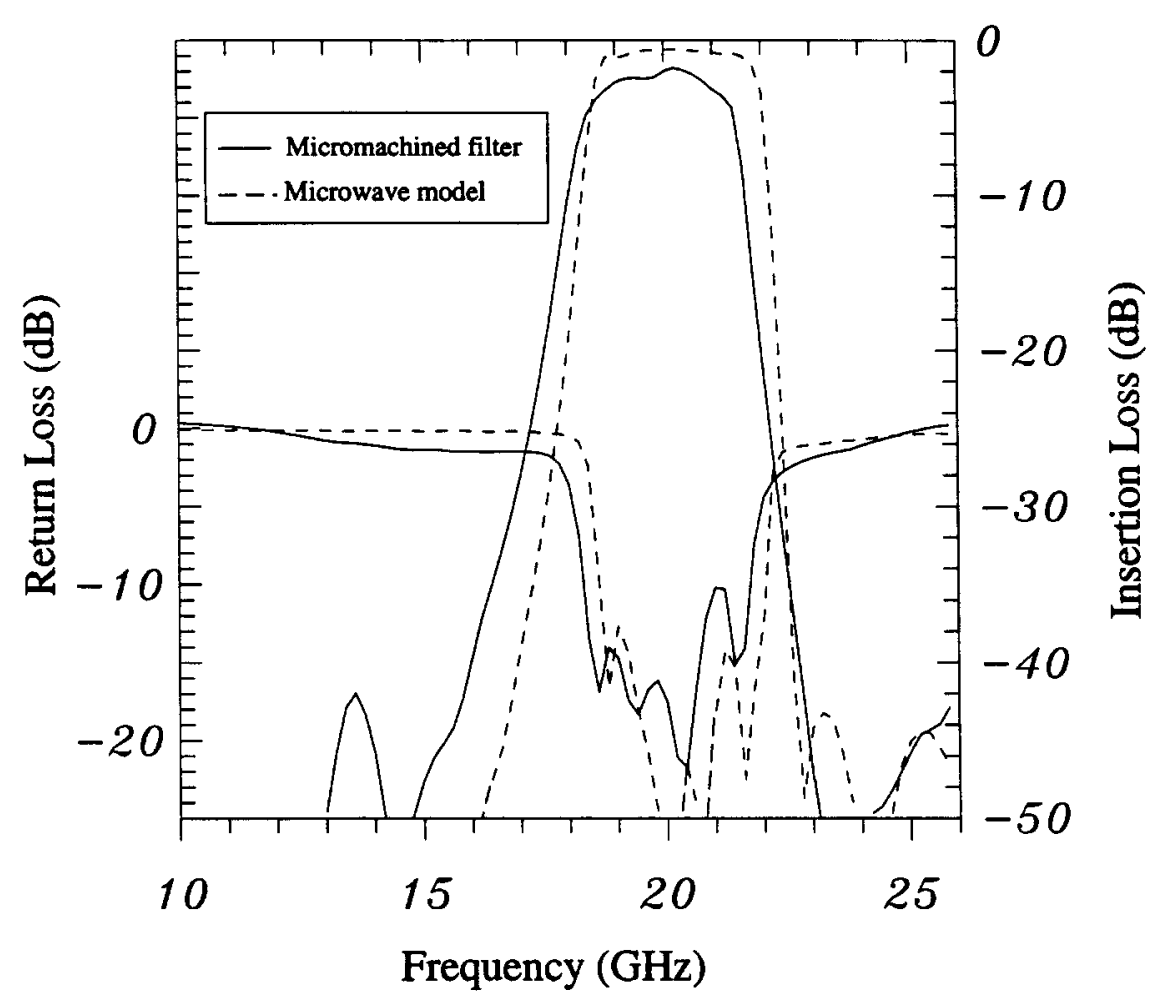

Figure 5. Measured response of the $20-\mathrm{GHz}$ micromachined interdigital filter.

croshield line can support a near-coplanar-waveguide field distribution when the slot dimensions are small compared to the height of the substrate, or a near-microstrip-field distribution when the slot dimensions are large compared to the height of the substrate. One can therefore choose the microshield line geometry to obtain a relatively simple transition between the microshield line and the feeding CPW line on the high-resistivity silicon/GaAs wafer, despite the large difference in the dielectric constants of the transmission media. Although rigorous optimization has not been conducted, designs based on a simple matching of quasistatic characteristic impedance values have demonstrated very good transitions from $\mathrm{CPW}$ to microshield and from GCPW to microshield up to $40 \mathrm{GHz}$ (see ref. 5 for more details).

\section{Effective Dielectric Constant}

Due to the air substrate of the microshield line, the effective dielectric constant, $\epsilon_{r, \text { eff }}$, is very close to 1.0. Because of the membrane, however, $\epsilon_{r, \text { eff }}$ is slightly increased because a fraction of the fields are contained within the thin dielectric layers. As shown in Figure 6, the measured $\epsilon_{r, \text { eff }}$ changes from around 1.09 to 1.15 as the slot width is reduced from 55 to $25 \mu \mathrm{m}$. The increase is a result of greater field confinement in the slot and thus in the membrane. It is expected that for a dielectric thickness smaller than $2.0 \mu \mathrm{m}$, and

TABLE II. Measured and Calculated Interdigital Membrane Filters Insertion Loss

\begin{tabular}{lccccc}
\hline $\begin{array}{l}\text { Bandwidth and } \\
\text { center frequency }\end{array}$ & $\begin{array}{c}Q_{U} \text { of } \\
\text { resonators }\end{array}$ & $\begin{array}{c}\text { Calculated } \\
\text { loss from } \\
\text { resonators }\end{array}$ & $\begin{array}{c}\text { Measured } \\
\text { loss from } \\
\text { feedlines }\end{array}$ & $\begin{array}{c}\text { Measured } S_{11} \\
\text { mismatch }\end{array}$ & $\begin{array}{c}\text { Calc./meas. } \\
\text { port-to-port } \\
\text { insertion loss }\end{array}$ \\
\hline $16 \%(20.3 \mathrm{GHz})$ & 330 & $0.80 \mathrm{~dB}$ & $0.6 \mathrm{~dB}$ & $0.15 \mathrm{~dB}$ & $1.55 \mathrm{~dB} / 1.70 \mathrm{~dB}$ \\
$16 \%(850 \mathrm{MHz})$ & 1610 & $0.16 \mathrm{~dB}$ & $0.3 \mathrm{~dB}$ & $0.14 \mathrm{~dB}$ & $0.60 \mathrm{~dB} / 0.70 \mathrm{~dB}$ \\
$40 \%(13.5 \mathrm{GHz})$ & 272 & $0.33 \mathrm{~dB}$ & $0.4 \mathrm{~dB}$ & $0.01 \mathrm{~dB}$ & $0.74 \mathrm{~dB} / 0.70 \mathrm{~dB}$ \\
$5 \%(15.2 \mathrm{GHz})$ & 290 & $1.25 \mathrm{~dB}$ & $0.4 \mathrm{~dB}$ & $0.35 \mathrm{~dB}$ & $2.00 \mathrm{~dB} / 2.00 \mathrm{~dB}$ \\
\hline
\end{tabular}



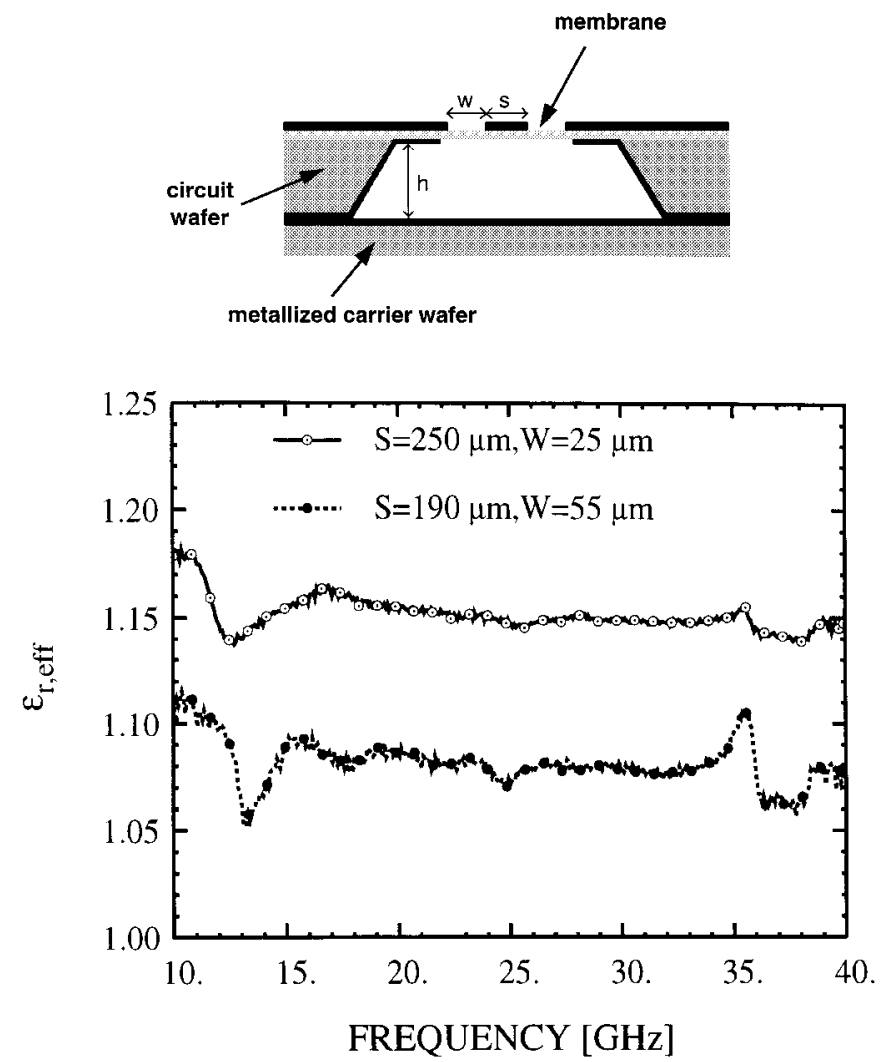

Figure 6. Cross-section view of a microshield line (top) and the measured $\epsilon_{r, \text { eff }}$ on two microshield lines with different aspect ratios (bottom). The cavity height is $350 \mu \mathrm{m}$.

for typical line geometries with a slot widths larger than $20 \mu \mathrm{m}, \epsilon_{r, \text { eff }}$ will remain lower than 1.20 , thereby ensuring nearly dispersion-free operation.

\section{Lowpass Filters at $\mathbf{3 0}$ and $\mathbf{9 0} \mathbf{~ G H z}$}

The stepped-impedance approach to lowpass filter design is well suited for applications which do not require a sharp roll-off in the insertion loss. Often, however, filter specifications call for high rejection over multiple-octave bandwidths, a requirement which may be difficult to meet using conventional substrate-supported lines due to the propagation of higher order modes. Thus, the very broad, single-mode bandwidth of the microshield line can provide superior filter performance in this respect.

Stepped-impedance filters using five, seven, and nine sections have been designed and tested at 30 $\mathrm{GHz}[5,21]$. The high and low impedance sections of the five-section filter are $265 \Omega$ and $45 \Omega$, respectively, while the feedline and filter center impedance are designed to be $75 \Omega$ (Fig. 7). The metalization thickness is $1 \mu \mathrm{m}$ and is sufficient for $30-\mathrm{GHz}$ operation. The membrane dimensions are $6 \times 1.8 \mathrm{~mm}^{2}$ with a cavity height of $350 \mu \mathrm{m}$. Notice that, in contrast to the interdigital filters, the microshield topology results in filter structures on long and narrow membranes. In Figure 7 , the measured data for a five-section, $0.5-\mathrm{dB}$ ripple Chebyshev filter are compared with results from a space-domain integral equation (SDIE) analysis method $[5,22]$. The rejection is greater than $20 \mathrm{~dB}$ up to $75 \mathrm{GHz}$, which is about 1.5 octaves above the $3-\mathrm{dB}$ point at $26 \mathrm{GHz}$. The measured $S_{21}$ is between 0.25 and $0.9 \mathrm{~dB}$ from 10 to $23 \mathrm{GHz}$. This is very close to the $0.5-\mathrm{dB}$ ripple design specification, and indicates that the attenuation is approximately $0.3 \mathrm{~dB}$ greater than predicted in the ideal, lossless model.

A lowpass filter is also designed at $90 \mathrm{GHz}$ using a stepped-impedance implementation of a seven-section 0.5-dB equal ripple Chebyshev filter [23]. The high- and low-impedance sections of the filter are $277 \Omega$ and $63 \Omega$, respectively, while the 


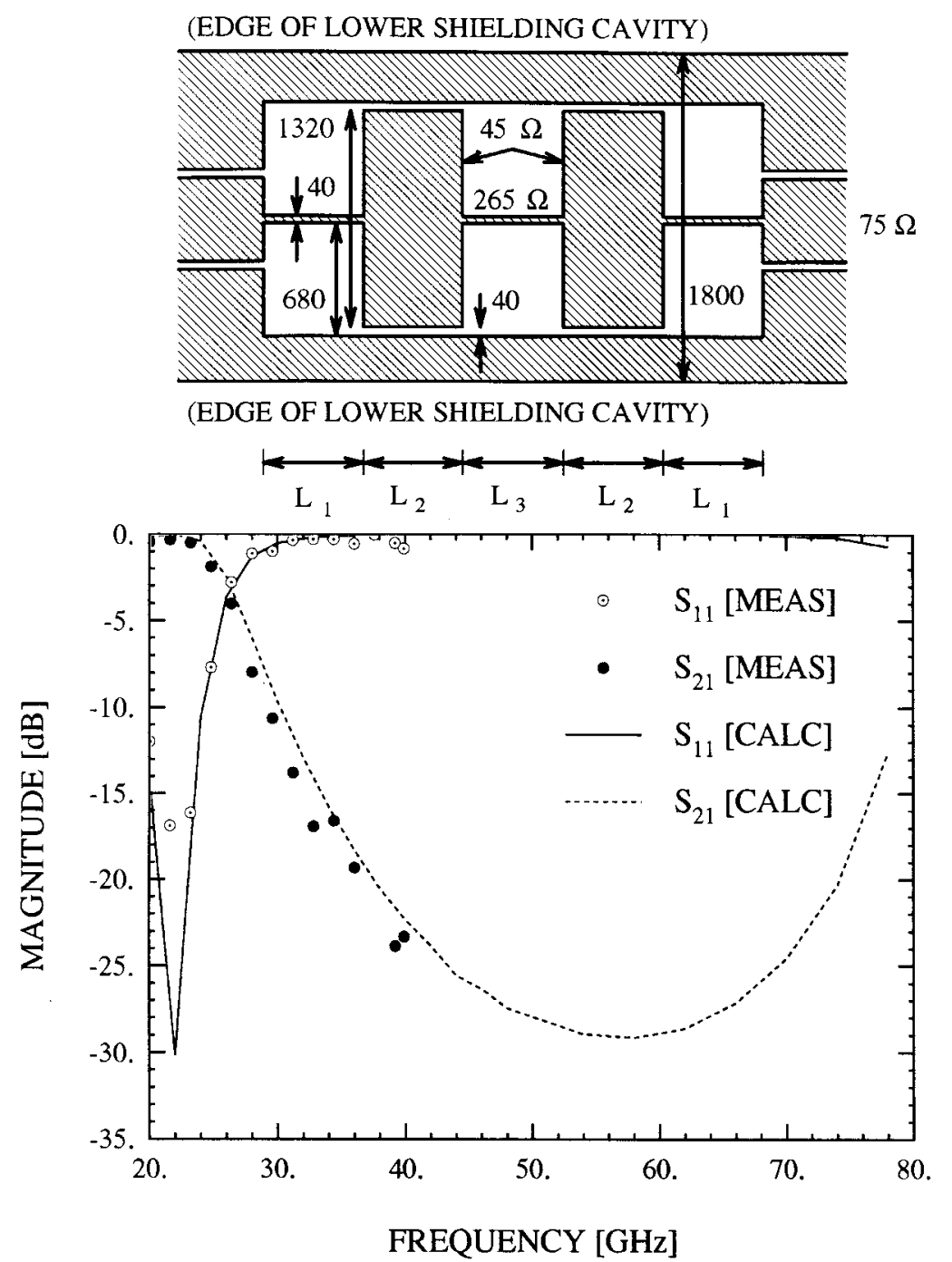

Figure 7. Measured and calculated (SDIE) $S$-parameters for a microshield lowpass filter at $30 \mathrm{GHz}$. The lengths of the different sections are $L_{1}=745, L_{2}=1200$, and $L_{3}=1189$. All dimensions are in microns.

feed line and filter center impedance are designed to be $92 \Omega$ (Fig. 8). For $W$-band measurements, it was found that the best results were achieved when the wafer probes were set as close as possible to the membrane edge. Furthermore, an impedance transformer was used to reduce the matching problems between the high-impedance membrane circuits and the 50- $\Omega$ cpw-probe impedance. For the $92-\Omega$ microshield line, a quarter-wavelength section at $90 \mathrm{GHz}$ of a $68-\Omega$ microshield line was used. The membrane dimensions are $4.3 \times 0.6 \mathrm{~mm}^{2}$ (including the input/output impedance transformers) with a cavity height of $355 \mu \mathrm{m}$. The measured response of the lowpass filter from 75 to $110 \mathrm{GHz}$ is shown in Figure 8 along with results of the FDTD analysis at
40-140 GHz. The filter achieves a cutoff frequency of approximately $90 \mathrm{GHz}$, with less than 1.0-dB passband insertion loss, and the FDTD technique accurately predicts the filter performance. The presence of the membrane is incorporated into the FDTD analysis with a relative dielectric constant of 1.08. It is important to note that the microshield lowpass filter provides around 20-dB better rejection than a comparable lowpass filter designed using GCPW lines on $100-\mu \mathrm{m}$ GaAs substrates [23].

The discrepancy between the measured and calculated data in both the $30-\mathrm{GHz}$ and $90-\mathrm{GHz}$ designs is due to the necessity to model this circuit with a single effective dielectric constant, even though the low- and high-impedance sec- 

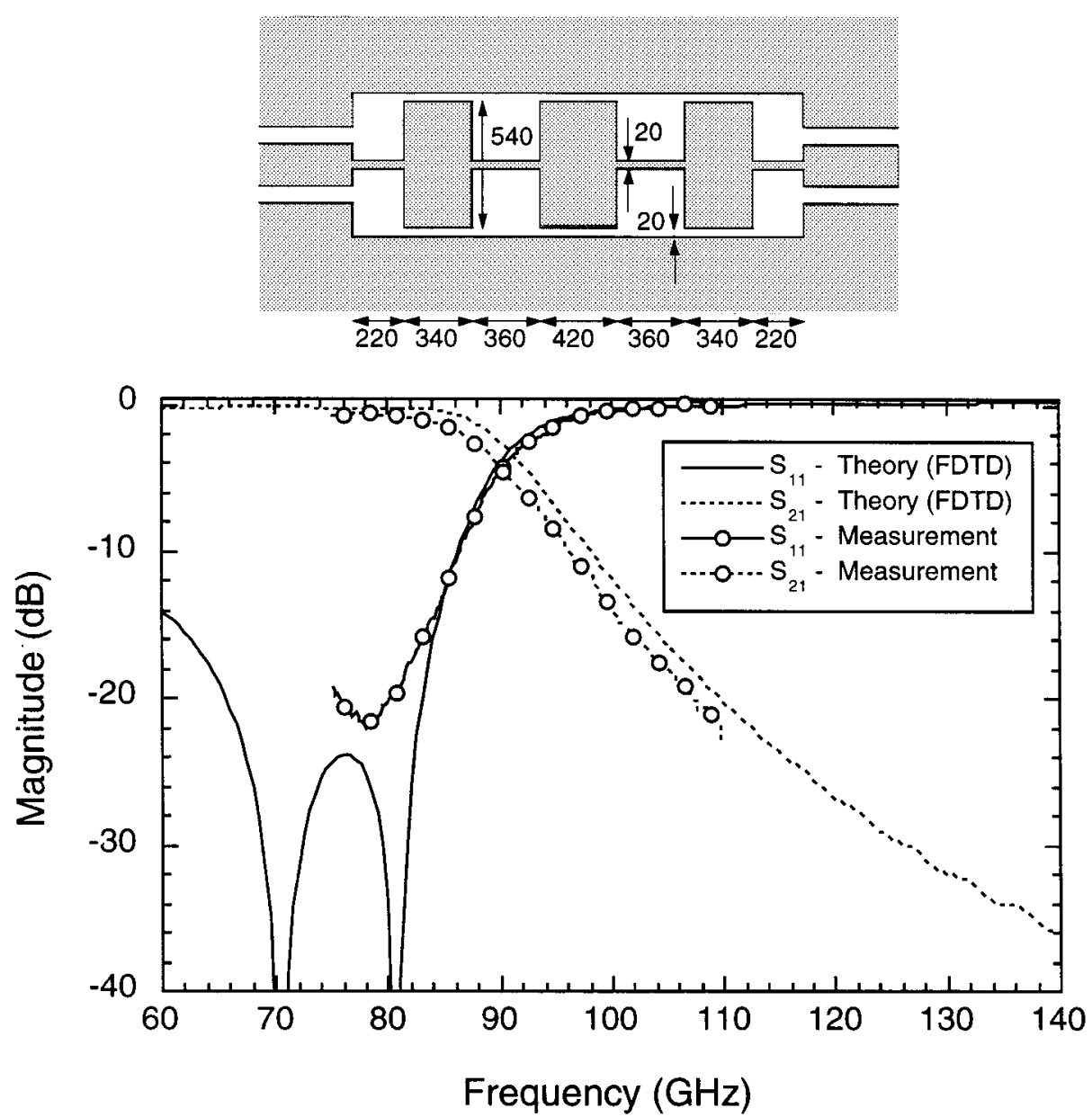

Figure 8. Measured and calculated (FDTD) $S$-parameters for a microshield lowpass filter at $90 \mathrm{GHz}$. All dimensions are in microns.

tions have drastically different slot widths. This can be solved in the future with the use of more flexible FDTD or SDIE analysis routines.

\section{Low-Loss Bandpass Filters at $30 \mathrm{GHz}$}

A variety of techniques exist for the implementation of bandpass filters. For CPW applications, filters using a combination of series and/or shunt tuning stubs have received considerable attention $[24,25]$. By cascading multiple open-end stubs in series, it is quite simple to realize a bandpass response with high out-of-band rejection and low-loss performance [26]. The passband resonance of an open-end series stub occurs when the mean length is $\lambda_{g} / 4$, and the associated radiation loss is very low due to the location of the stub within the center conductor. The stopband resonance occurs when the stub length is $\lambda_{g} / 2$ and is considerably stronger than the passband resonance. Due to the long narrow slots encountered in the series stub designs (around $20 \times 2000 \mu \mathrm{m}$ ), the effective dielectric constant of the microshield line in a series stub configuration is increased from 1.08 to 1.40 [5, 14].

A three-section open-end series stub bandpass filter was fabricated using the stub dimensions given in Figure 9, with each section separated by $150 \mu \mathrm{m}$ [5]. The filter is centered at $29 \mathrm{GHz}$ with a $55 \%$ bandwidth. The total dimensions of the filter are $0.80 \lambda_{g}$ long at $29 \mathrm{GHz}(7.5 \mathrm{~mm})$ and $300 \mu \mathrm{m}$ wide. The measured response, shown in Figure 9, has an insertion loss of only $1.0 \mathrm{~dB}$ from 22 to $32 \mathrm{GHz}$, which is competitive with the best waveguide bandpass filters using suspended stripline [27]. The calculated data are generated by using the scattering parameters found from the full-wave analysis of a single stub and treating 


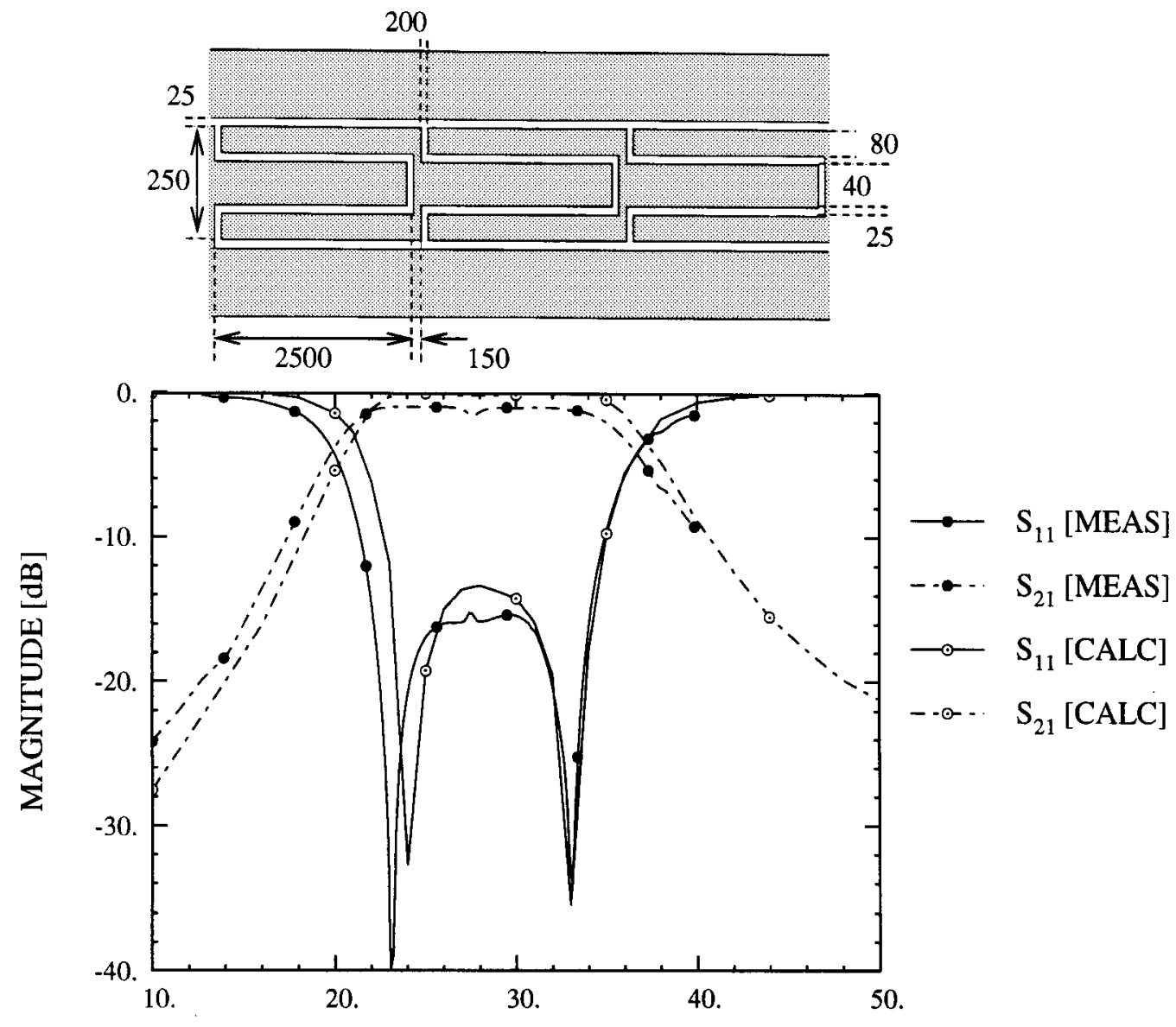

FREQUENCY [GHz]

Figure 9. Measured and calculated (SDIE) $S$-parameters for a microshield bandpass filter which consists of three open-end series stubs. The distance between the stubs is only $150 \mu \mathrm{m}$. All dimensions are in microns.

the filter as three noncoupled elements in series. The agreement between the measured and calculated performance is quite good and indicates that there is very little electromagnetic coupling between the stubs, even though the stub separation is only $150 \mu \mathrm{m}$.

A compact bandpass filter has also been demonstrated and is based on the folded open-end series stub pioneered by Weller et al. [14, 28]. This stub offers comparable performance to the standard series open-end stub described previously but at a fraction of the size. A five-section folded open-end series stub bandpass filter was fabricated using the dimensions given in Figure 10. The filter is centered at $25 \mathrm{GHz}$ with a $40 \%$ bandwidth. The total dimensions of the filter are $0.53 \lambda_{g}$ in length at $25 \mathrm{GHz}(5.5 \mathrm{~mm})$ and $300 \mu \mathrm{m}$ in width. The measured response shows an inser- tion loss of $1.0 \mathrm{~dB}$ from 21 to $29 \mathrm{GHz}$ (Fig. 10). It is immediately apparent that the five-section folded stub filter provides better out-of-band rejection than the three-section filter described previously and at $65 \%$ of the longitudinal size. The performance of this filter is also competitive with the best suspended stripline waveguide filters.

\section{The 250-GHz Bandpass Filter}

The microshield line has been also applied to submillimeter-wave components $(100-1000 \mathrm{GHz})$. As is well known, this frequency range is of importance to radio-astronomical receivers and space-based remote sensing of upper atmospheric pollutants [29]. The associated components, such as receivers, filters and couplers, are built in 

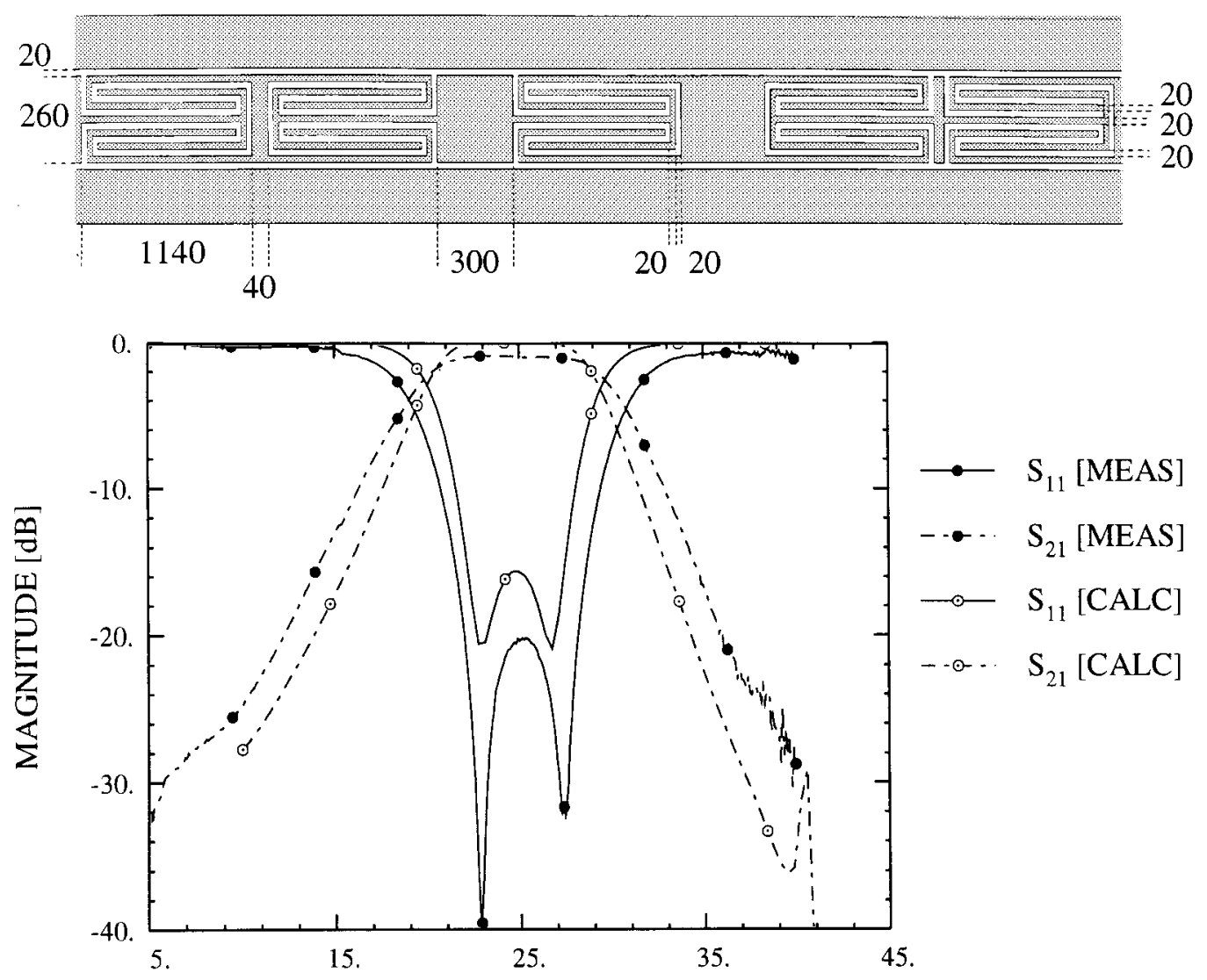

\section{FREQUENCY [GHz]}

Figure 10. Measured and calculated (SDIE) $S$-parameters for a microshield bandpass filter which consists of five folded open-end series stubs. The filter length is $0.5 \lambda_{g}$ at $25 \mathrm{GHz}$. All dimensions are in microns.

waveguides or in bulky quasi-optical systems. This leads to extremely expensive components and has retarded the use of this frequency for commercial applications such as very compact collisionavoidance radars. The microshield line, or membrane supported lines in general, are ideal for applications in this frequency range. They offer wideband, low-loss, dispersion-free performance and are easy to fabricate because the membrane dimensions are very small (less than $1 \mathrm{~mm}$ in length in many cases).

The microshield line was utilized to fabricate the first planar bandpass filter at $250 \mathrm{GHz}$ [30]. The bandpass filter has a relative bandwidth of $58 \%$ and utilizes four quarter-wavelength openend series stubs with the second and fourth stubs reversed relative to the first and third stub (Fig. 11). The effective dielectric constant of the stubs was estimated to be 1.36 due to the small dimensions of the slots $(10 \mu \mathrm{m})$ and the stub lengths were sized accordingly to resonate at $250 \mathrm{GHz}$. The filter is $1 \mathrm{~mm}$ in length, which is around 0.8 $\lambda_{g}$ at $250 \mathrm{GHz}$. The microshield filter is placed in a cavity and for the dimensions given in Figure 11 , the dominant waveguide mode cut-off frequency is greater than $500 \mathrm{GHz}$.

The filter is attached to a cpw-fed doublefolded slot (DFS) antenna which receives power from a calibrated plane wave. RF detection is achieved using planar bismuth microbolometers after the microshield filter [31]. The DFS antenna has a relative bandwidth of $20 \%$, so three circuits with three different antennas centered at 170 $\mathrm{GHz}, 250 \mathrm{GHz}$, and $340 \mathrm{GHz}$ and the same microshield filter were fabricated. The bolometers of each circuit were absolutely calibrated and resulted in a responsivity around $2 \mathrm{~V} / \mathrm{W}$. As a means of calibration, measurements are first taken on a circuit with no filter and a simple microshield straight line, and then measurements 


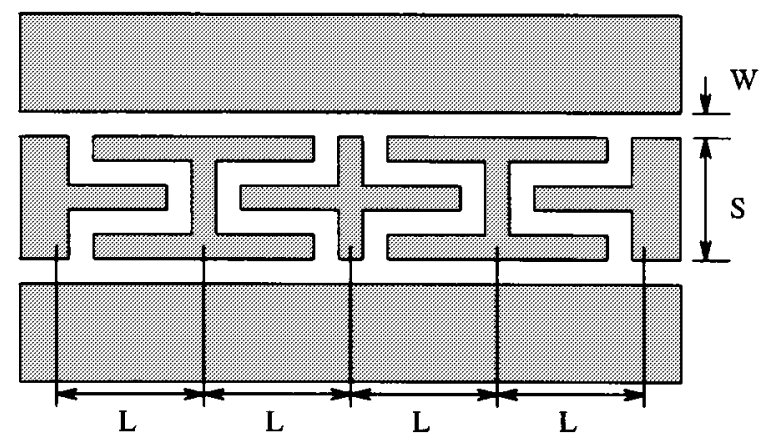

(a)

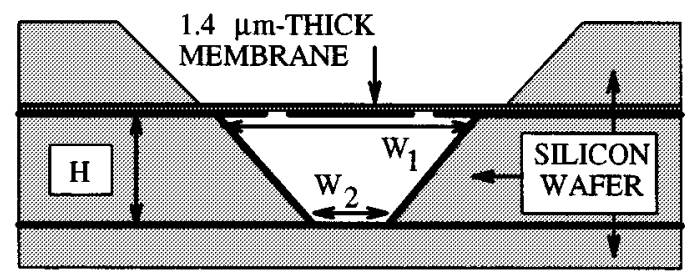

(b)

Figure 11. The four-section microshield bandpass filter (not to scale). The metalization pattern is shown in (a), where $L=250, S=50$, and $W=10$. A cross-sectional view is shown in (b), where $H=200, W_{1}=320$, and $W_{2}=40$. In (b), metalization is indicated by the dark lines. All dimensions are in microns.

are taken on the circuit with the microshield filter. Details of the extraction of the $S$-parameters of the filter are presented elsewhere [14, 30], and the measured results show a $1.0-1.5-\mathrm{dB}$ passband insertion loss (Fig. 12). It is also seen that the low-frequency stopband provides excellent rejection. This confirms that high-performance planar circuits on thin dielectric membranes are excellent for millimeter- and submillimeter-wave systems.

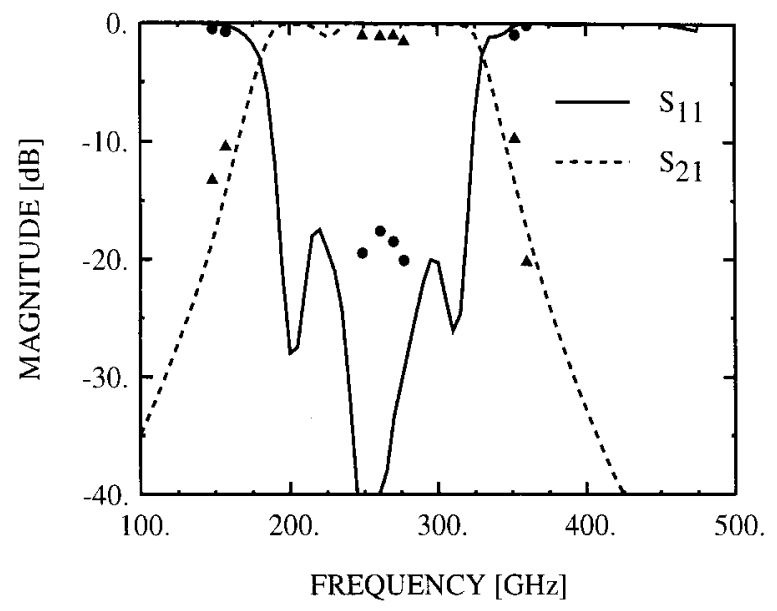

Figure 12. Comparison between the results extracted from raw measured data at $150-350 \mathrm{GHz}$ (markers) and the predicted filter response from the SDIE analysis (lines).

\section{W-BAND SHIELDED MICROSTRIP BANDPASS FILTERS}

Membrane-based transmission lines were recently applied in a shielded membrane microstrip (SMM) configuration to build coupled-line bandpass filters at $W$-band frequencies. The geometry resembles that of suspended stripline, but the conducting strip is not positioned symmetrically between the two ground planes. For SMM, the micromachined top cavity actually provides the ground plane for the microstrip signal and the middle circuit wafer results on a metalized carrier wafer which acts as a shield (Fig. 13). The cover height, $h_{c}$, is determined by the thickness of the circuit wafer, and the signal-to-ground separation, $h$, is determined by the etched depth of the micromachined top cavity.

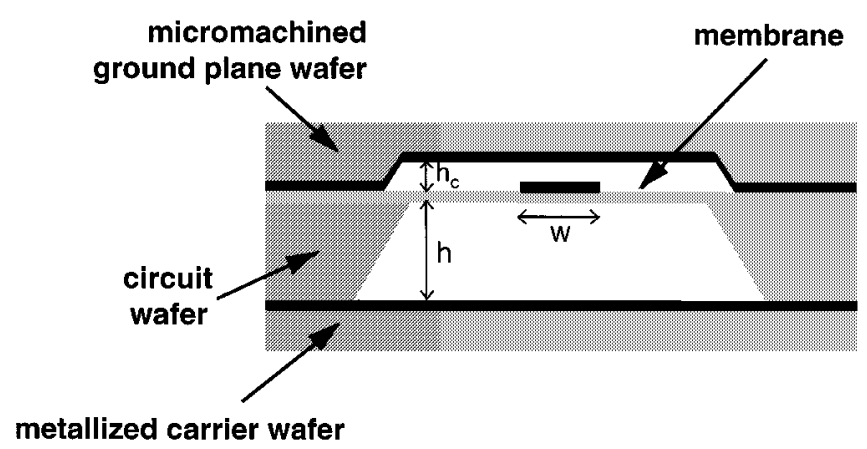

Figure 13. The shielded membrane microstrip geometry. Notice that the RF ground plane is actually on top of the microstrip line. 
The propagating mode of the SMM line is characterized by an electric field orientation which is primarily vertical with respect to the plane of the signal line. Conversely, a horizontally opposed electric field orientation prevails in a CPW-style wafer probe. A candidate for a transition between these two modes is the microshield line, which has shown the ability to support both $\mathrm{CPW}$-like and a microstrip-like modes [5]. This is a very convenient solution, because there is an impedance mismatch between the $50-\Omega$ wafer probe and the $90-\Omega$ SMM line, and a Klopfensteintapered section of microshield line can also be used to accomplish the impedance matching function [32]. The taper length is $100^{\circ}$ (around $\lambda_{g} / 4$ ) at the lowest frequency of interest.

The bandpass filters of this work are based on coupled-line resonator designs derived from equal ripple Chebyshev prototypes and a center impedance of $90 \Omega$ [23]. A commercially available software package (PARFIL [33]) was used to synthesize the filter geometry for a ground plane separation and an upper shield separation of 100 $\mu \mathrm{m}$ and $500 \mu \mathrm{m}$, respectively, and the final filter dimensions were chosen after experimental iteration on a $2-\mathrm{GHz}$ scale model. Figure 14 shows a fabricated coupled-line bandpass filter centered at $94 \mathrm{GHz}$. The microstrip line is $180 \mu \mathrm{m}$ wide and results in an impedance of $90 \Omega$. The membrane dimensions are $11 \mathrm{~mm}$ long $\times 2.5 \mathrm{~mm}$ wide. The measured results show low passband inser- tion loss, a very sharp roll-off, and high out-ofband attenuation. A filter designed for $4.25 \%$ bandwidth achieves a passband insertion loss of $3.4 \mathrm{~dB}$ and a bandwidth of $6.1 \%$ at a center frequency of $94.7 \mathrm{GHz}$ (Fig. 15). To our knowledge, these results represent state-of-the-art performance at $94 \mathrm{GHz}$.

Measured $S$-parameters of the bandpass filter reveal a wider bandwidth than the designed value. The reason is that the distance from the signal line to the ground plane was approximately 20 $\mu \mathrm{m}$ larger than the $100-\mu \mathrm{m}$ depth of the ground cavity. This is verified by the good agreement with the FDTD analysis (Fig. 15), which was performed using a ground plane separation of 120 $\mu \mathrm{m}$ and the measured value of $\epsilon_{r, \text { eff }}(1.04)$ for the SMM line.

\section{CONCLUSIONS AND FUTURE WORK}

It is evident that state-of-the-art filters can be manufactured at low cost using membrane-based transmission lines. The filters achieved so far are just a small sample of the performance potential of this micromachining technology. The micromachined filters are compatible with IC fabrication techniques and can be fabricated in large numbers for low cost applications. The micromachined filters can also be combined with planar diodes and transistors to result in active filter

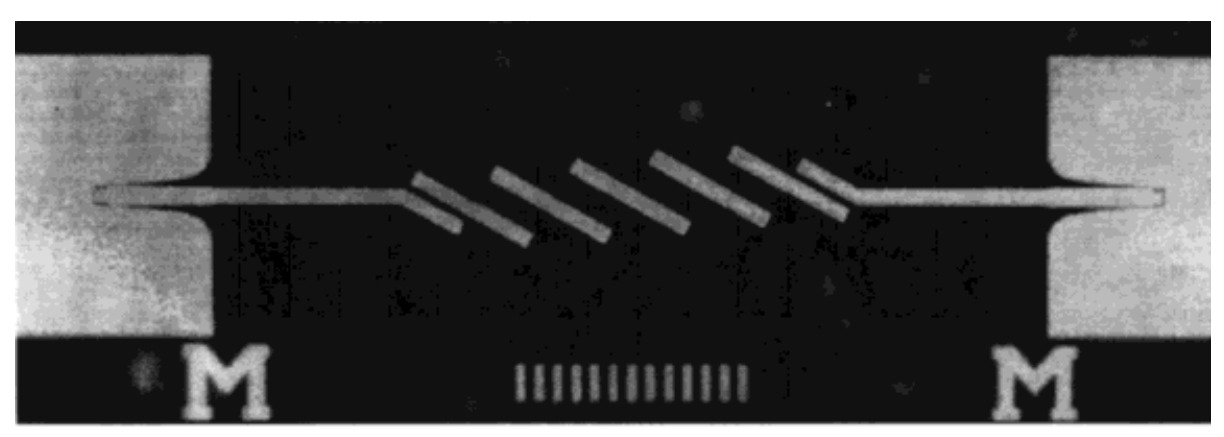

\begin{tabular}{|c|c|c|}
\hline Section & Width $(\mu \mathrm{m})$ & Separation $(\mu \mathrm{m})$ \\
\hline \hline 1,6 & 160 & 70 \\
\hline 2,5 & 180 & 270 \\
\hline 3,4 & 180 & 300 \\
\hline
\end{tabular}

Figure 14. The $6 \%$ shielded membrane microstrip bandpass filter with associated dimensions. All resonators are $710 \mu \mathrm{m}$ in length. The tapered sections at the input/output are the Klopfenstein microshield transformers between the microstrip mode on the membrane and the GCPW mode on the silicon wafer. 


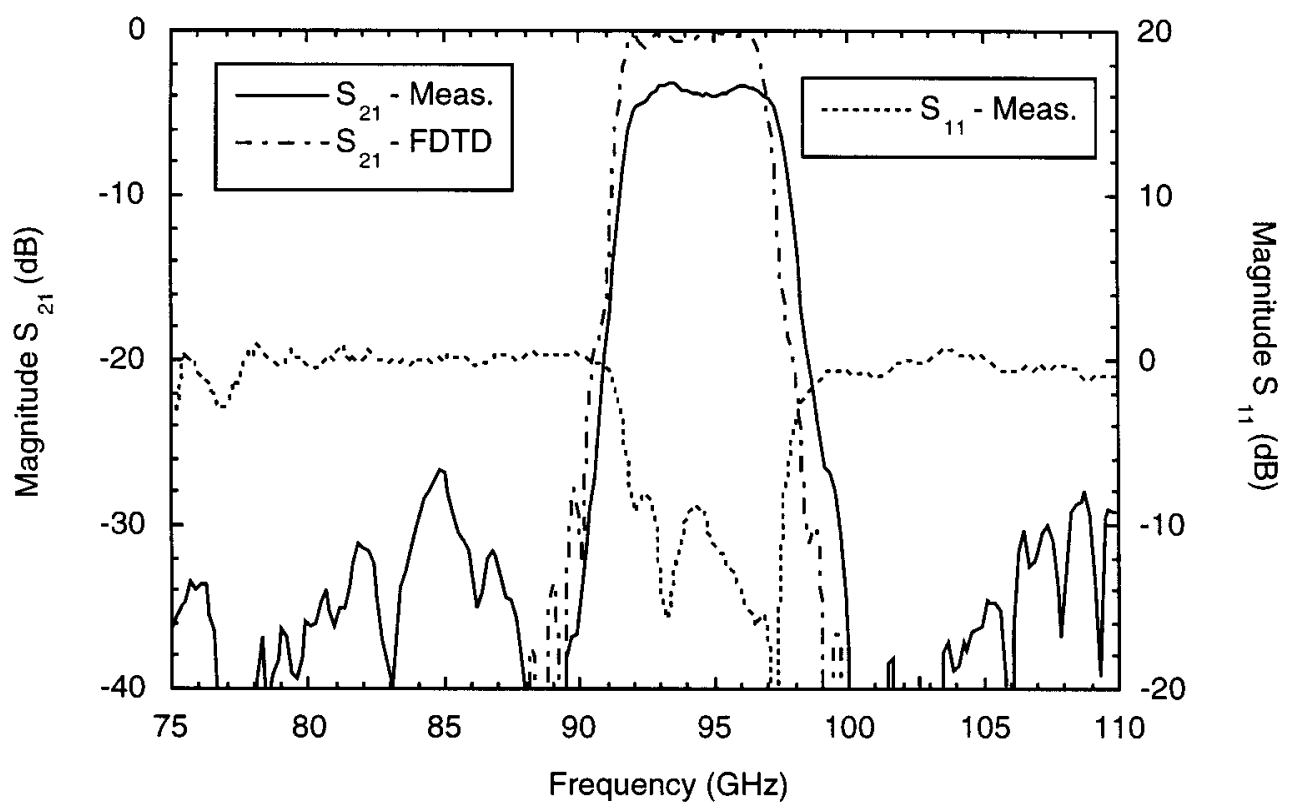

Figure 15. Measured and calculated (FDTD) $S$-parameters for the filter shown in Figure 14.

networks and low phase noise oscillators. The application areas are in $\mathrm{K}, \mathrm{Ka}$ and $\mathrm{Ku}$-band satellite communication systems, direct broadcast satellite systems at $12.5 \mathrm{GHz}$, wireless base station systems, and the emerging millimeter-wave indoor/outdoor communication systems at 38 and $60 \mathrm{GHz}$. Furthermore, the micromachined filters can be used in 35- and 94-GHz radar systems and millimeter- $(94 \mathrm{GHz})$ and submillimeter-wave (180-GHz, 230-GHz, etc.) radiometric systems for aircraft landing systems and atmospheric remote sensing applications.

The underlying theory of the micromachined filter is not complex due to the thin dielectric membranes and the resulting low dielectric constant ( $\epsilon_{r, \text { eff }}$ from 1.04 to 1.40). Excellent results were achieved with simple scale modeling around $1 \mathrm{GHz}$ for the case of suspended stripline filters, and accurate theoretical models were achieved with the SDIE method in the case of microshield lines, or with FDTD analysis, as in the case of the shielded membrane microstrip lines. Obviously, it would be advantageous to have the numerical flexibility of changing the effective dielectric constant for each section of the microshield (or SMM) filter and this can be easily done in the future. Another refinement of the theory could be to model accurately the sloping sidewalls. These sidewalls are generally far enough from the circuit region of interest that they are currently modeled as vertical sidewalls. However, if filter miniaturization is a goal, then correct modeling of the sidewalls and the surrounding via holes near the membrane edge must be done to obtain an accurate model.

The future work in micromachined filters is shaping up in two independent areas. The first one is the continuation of the present work on thin dielectric membranes and the construction of ever better and smaller filters and components. Varactor tuned interdigital filters and micromachined high-isolation filter banks for wideband radar/receiver applications are currently being investigated at $10-20 \mathrm{GHz}$. Also, miniature folded resonators on membranes coupled with lumpedelement MIM (metal-insulator-metal) capacitors are being investigated at $30 \mathrm{GHz}$. The membrane technology is not limited to transmission lines and filters alone, and wideband Lange-type couplers from 6-20 GHz [34], low-loss Wilkinson couplers at $33 \mathrm{GHz}$ [35], high-frequency inductors and capacitors [20], coupled-line couplers covering the $20-110-\mathrm{GHz}$ frequency range [36], and high isolation single sideband mixers at $18 \mathrm{GHz}$ [34] have been achieved on thin dielectric membranes. More work will be done in this area for the construction of low-power SSB mixers at 60 and $94 \mathrm{GHz}$, low-loss power combining networks at 30 and $94 \mathrm{GHz}$, and active filters and multiplexers for satellite applications.

The second area of research involves a fundamental rethinking of the role of the solid-state 
wafer. It is about viewing a high-resistivity wafer not as a planar surface but as a three-dimensional bulk which is ready to be etched to reveal threedimensional cavities, photonic crystals, resonators, couplers, probes, and shields. We call it 3-D microwave micromaching and micropackaging and are actively pursuing it at the University of Michigan, Ann Arbor.

\section{ACKNOWLEDGMENTS}

The work presented in this article was initiated under the NASA Center for Space Terahertz Technology at the University of Michigan and by National Science Foundation Presidential Young Investigator Awards (Profs. Rebeiz and Katehi). It was continued with strong support from the Army Research Office, Electronics Division, the Office of Naval Research. It has also been supported by the Pluto Express Program and the President's Fund at the NASA Jet Propulsion Laboratory.

\section{REFERENCES}

1. R. S. Muller et al. (eds.), Microsensors. IEEE Press, New York, 1991.

2. G. M. Rebeiz, D. P. Kasilingam, P. A. Stimson, Y. Guo, and D. B. Rutledge, "Monolithic MillimeterWave Two-Dimensional Horn Imaging Arrays," IEEE Trans. Ant. Propag., Vol. AP-28, Sept. 1990, pp. $1473-1482$.

3. W. Y. Ali-Ahmad and G. M. Rebeiz, "An 86-106 $\mathrm{GHz}$ Quasi-Integrated Low-Noise Receiver," IEEE Trans. Microwave Theory Tech., Vol. MTT-41, No. 4, April 1993, pp. 558-564.

4. N. I. Dib, W. P. Harokopus, L. P. B. Katehi, C. C. Ling, and G. M. Rebeiz, "Study of a Novel Planar Transmission Line," IEEE MTT-S Int. Microwave Symp., 1991, pp. 623-626.

5. T. M. Weller, L. P. B. Katehi, and G. M. Rebeiz, "High Performance Microshield Line Components," IEEE Trans. Microwave Theory Tech., Vol. MTT-43, No. 3, March 1995, pp. 534-543.

6. R. W. Jackson, "Considerations in the Use of Coplanar Waveguide for Millimeter-Wave Integrated Circuits," IEEE Trans. Microwave Theory Tech., Vol. MTT-34, No. 12, Dec. 1986, pp. 1450-1456.

7. H. Cheng, J. F. Whitaker, T. M. Weller, and L. P. B. Katehi, "Terahertz-Bandwidth Characterization of Coplanar Waveguide via Time-Domain ElectroOptic Sampling," IEEE MTT-S Int. Microwave Symp., 1994, pp. 477-480.

8. Dr. Robert Haas, Aeroject Electrosystems, 1991.

9. Dr. Marti Hermann, NASA Jet Propulsion Laboratory, 1995.

10. L. I. Maissel and R. Glang, Handbook of Thin Film Technology. McGraw-Hill, New York, 1970.
11. S. S. Gearhart, Integrated Millimeter-Wave and Submillimeter-Wave Antennas and Schottky-Diode Receivers, Ph.D. thesis, University of Michigan, Ann Arbor, MI, 1994.

12. K. E. Peterson, "Silicon As a Mechanical Material," Proc. IEEE, Vol. 70, 1982, pp. 420-457.

13. R. E. Williams, Gallium Arsenide Processing Techniques. Artech House, Norwood, MA, 1984.

14. T. W. Weller, Micromachined High Frequency Transmission Lines on Thin Dielectric Membranes, Ph.D. thesis, University of Michigan, Ann Arbor, MI, 1995.

15. C. Y. Chi and G. M. Rebeiz, "Conductor-Loss Limited Stripline Resonators and Filters," IEEE Trans. Microwave Theory Tech., Vol. MTT-44, April 1996, pp. 626-630.

16. C. Y. Chi, Planar Microwave and Millimeter-Wave Components Using Micromachining Technologies, Ph.D. thesis, University of Michigan, Ann Arbor, MI, 1995.

17. G. L. Matthaei, L. Young, and E. M. T. Jones, Microwave Filters, Impedance-Matching Networks and Coupling Structures. Artech House, Norwood, MA, 1980, pp. 651-723.

18. E. Tuncer, B. T. Lee, M. S. Islam, and D. P. Neikirk, "Quasi-Static Conductor Loss Calculations in Transmission Lines Using a New Conformal Mapping Technique," IEEE Trans. Microwave Theory Tech., Vol. MTT-42, Sept. 1994, pp. $1807-1815$.

19. G. L. Matthaei, "Interdigital Band-Pass Filters," IRE Trans. Microwave Theory Tech., Vol. 10, Nov. 1962, pp. 479-491.

20. C. Y. Chi and G. M. Rebeiz, "Planar Microwave and Millimeter-Wave Lumped Elements and Coupled-Line Filters Using Micromachining Techniques," IEEE Trans. Microwave Theory Tech., Vol. MTT-43, No. 4, April 1995, pp. 730-738.

21. T. M. Weller, G. M. Rebeiz, and L. P. Katehi, "Experimental Results on Microshield Transmission Line Circuits," IEEE MTT-S Int. Microwave Symp., 1993, pp. 827-830.

22. N. I. Dib, L. P. Katehi, G. E. Ponchak, and R. N. Simons, "Theoretical and Experimental Characterization of Coplanar Waveguide Discontinuities for Filter Applications," IEEE Trans. Microwave Theory Tech., Vol. MTT-39, No. 5, May 1991, pp. 873-882.

23. S. V. Robertson, L. P. Katehi, and G. M. Rebeiz, "Micromachined W-band Filters," IEEE Trans. Microwave Theory Tech., Vol. MTT-44, April 1996, pp. 598-606.

24. K. Hettak, et al., "A New Uniplanar Bandpass Filter Using $\lambda_{g} / 2$ Slotline and $\lambda_{g} / 4$ Coplanar Waveguide Resonators," Proceedings of the 1994 European Microwave Conference, 1994, pp. 1360-1366.

25. Y. Noguchi, et al., "A New Compact $\lambda_{g} / 4$ Coplanar Waveguide Resonator Bandpass Filter," Pro- 
ceedings of the 1993 European Microwave Conference, 1993, pp. 631-633.

26. D. F. Williams and S. E. Schwarz, "Design and Performance of Coplanar Waveguide Bandpass Filters," IEEE Trans. Microwave Theory Tech., Vol. 31, No. 7, July 1983, pp. 558-568.

27. W. Menzel, "Broadband Filter Circuits Using an Extended Suspended Substrate Transmission Line Configuration," Proceedings of the 22nd European Microwave Conference, 1992, pp. 459-463.

28. T. M. Weller and L. P. Katehi, "Miniature Stub and Filter Designs Using the Microshield Transmission Line," IEEE MTT-S Int. Microwave Symp., 1995, pp. 675-678.

29. IEEE Proceedings Special Issue on Terahertz Technology, Vol. 80, No. 11, Nov. 1992, pp. 1657-1864.

30. T. M. Weller, L. P. B. Katehi, and G. M. Rebeiz, "A $250 \mathrm{GHz}$ Microshield Bandpass Filter," IEEE Microwave Guided-Wave Lett., Vol. 5, No. 5, May 1995, pp. 153-155.
31. D. P. Neikirk, W. W. Lam, and D. B. Rutledge, "Far-Infrared Microbolometer Detectors," Int. J. Infrared Millimeter Waves, Vol. 5, 1984, pp. 245-276.

32. R. W. Klopfenstein, "A Transmission Line Taper of Improved Design," Proc. IRE, Vol. 44, Jan. 1956, pp. 31-35.

33. WaveCon Software, El Segundo, CA.

34. C. Y. Chi and G. M. Rebeiz, "Design of Lange Couplers and Single-Sideband Mixers Using Micromachining Techniques," IEEE Trans. Microwave Theory Tech. (to appear).

35. T. M. Weller, L. P. Katehi, M. I. Herman, and P. D. Wamhof, "Membrane Technology (MIST-T) Applied to Microstrip: A $33 \mathrm{GHz}$ Wilkinson Power Divider," IEEE MTT-S Int. Microwave Symp., 1994, pp. 911-914.

36. S. V. Robertson, L. P. Katehi, and G. M. Rebeiz, "A 20-40 GHz Micromachined Directional Coupler," IEEE MTT-S Int. Microwave Symp., 1996, pp. 797-800.

\section{BIOGRAPHIES}

Gabriel M. Rebeiz (senior member, IEEE) earned his $\mathrm{PhD}$ in electrical engineering from the California Institute of Technology in June 1988. He joined the faculty of the University of Michigan in September 1988 and was promoted to associate professor in September 1992. Prof. Rebeiz received the National Science Foundation Presidential Young Investigator Award in April 1991 and the URSI International Isaac Koga Gold Medal Award for Outstanding International Research in August 1993. He also received the Research Excellence Award in April 1995 from the University of Michigan. Together with his students, he is the winner of best paper awards at JINA'90, IEEE-MTT'92, '94, '95, '96 and IEEE-AP'92, '95. Prof. Rebeiz is an elected member of URSI-D. He was a visiting professor at Chalmers University of Technology in 1992, and a visiting professor at the Ecole Normale Superieur in 1993. He is the author of 70 articles published in refereed journals and more than 110 papers presented in National and International Conferences. Prof. Rebeiz interests are in applying micromachining techniques in silicon and GaAs for the development of low-loss and low-cost microwave antennas, components and subsystems for wireless applications, and satellite communication systems. Prof. Rebeiz is also interested in the development of planar collision-avoidance sensors for automotive applications, and in millimeter-wave imaging arrays, monopulse tracking systems, and phased arrays. (Photo not available.)

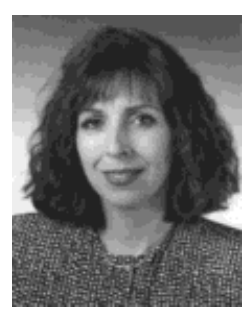

Linda P. B. Katehi received her BSEE degree from the National Technical University of Athens, Greece, in 1977 and her MSEE and PhD degrees from the University of California, Los Angeles, in 1981 and 1984, respectively. In September 1984, she joined the faculty of the EECS Department of the University of Michigan, Ann Arbor. Since then she has been interested in the development and characterization (theoretical and experimental) of microwave and millimeter-wave printed circuits, the computer-aided design of VLSI interconnects, the development and characterization of micromachined circuits for millimeter-wave and submillimeter-wave applications, and the development of low-loss lines for terahertz-frequency applications. She has also been theoretically and experimentally studying various types of uniplanar radiating structures for hybrid monolithic and monolithic oscillator and mixer designs. She has been awarded the IEEE AP-S W. P. King distinction (Best Paper Award for a Young Engineer) in 1984, the IEEE AP-S S. A. Schelkunoff Award (Best Paper Award) in 1985, the NSF Presidential Young Investigator Award and an URSI Young Scientist Fellowship in 1987, the Humboldt Research Award and The University of Michigan Faculty Recognition Award in 1994, and the IEEE MTT-S Microwave Prize in 1996. She is a Fellow of IEEE, and a member of IEEE AP-S, MTT-S, Sigma XI, Hybrid Microelectronics, URSI Commission D, and a member of AP-S ADCOM from 1992 to 1995 . Also, Prof. Katehi is an associate editor for the IEEE Transactions on AP-S and MTT-S.

Thomas M. Weller received the $\mathrm{BS}$, MS, and $\mathrm{PhD}$ degrees in electrical engineering in 1988, 1991, and 1995, respectively, from the University of Michigan, Ann Arbor. He is currently an assistant professor in the Electrical Engineering Department at the University of South Florida, Tampa. His current research involves micromachining applications for microwave and millimeter-wave circuits, hybrid and MMIC packaging, numerical modeling, and millimeter-wave sensors. (Photo not available.) 
Chen-Yu Chi was born in Tapei, Taiwan, in September 1964. He received the BS and MS degrees in electrical engineering from the National Chiao Tung University, Taiwan, in 1986 and 1988, respectively, and in 1994, he earned the $\mathrm{PhD}$ degree in electrical engineering from the University of Michigan, Ann Arbor. His thesis was on the development of novel micromachined filters and components at microwave and millimeterwave frequencies. He is currently working at Qualcomm Inc., San Diego, CA, in the development of portable telephone units for the AMPS and PCS bands. (Photo not available.)
Stephen V. Robertson received the BSEE degree from the University of Texas, Austin, Texas, and the MSE degree from the University of Michigan, Ann Arbor, in 1991 and 1993, respectively. $\mathrm{He}$ is currently pursuing his $\mathrm{PhD}$ degree in electrical engineering at the University of Michigan. His research interests lie in the development of novel micromachined structures for planar and quasi-planar millimeter-wave applications. (Photo not available.) 